\title{
MANETs: QoS and Investigations on Optimized Link State Routing Protocol
}

\author{
Lakshman Naik.L \\ Indian Institute of Technology (Banaras Hindu University) /Department of Electronics Engg., Varanasi, 221005, India \\ E-mail: lnaikl@bhu.ac.in \\ R.U.Khan ${ }^{1}$ and R.B.Mishra ${ }^{2}$ \\ Indian Institute of Technology (Banaras Hindu University)/Dept. of Electronics Engg. ${ }^{1}$, Dept. of Computer Science and \\ Engg. ${ }^{2}$, Varanasi 221005, India \\ E-mail: \{rukhan.ece, mishravi.cse\}@iitbhu.ac.in
}

Received: 13 June 2018; Accepted: 05 September 2018; Published: 08 October 2018

\begin{abstract}
Mobile Ad-Hoc Networks (MANETs) are self-forming, self-healing new generation infrastructure less wireless networks. Principal behind these networks is multi hop radio relaying. MANETs are very useful at locations where networking infrastructure is not available. Major applications of these networks can be accessed at military and emergency rescue operations. MANETs may contain small or large set of network nodes; each and every node requires acting as host and the router. Due to random movements of the nodes, MANETs obtain dynamic network topologies. Routing protocols in MANETs are accountable for establishing efficient and error free communication paths between network nodes. Dynamic network topologies make routing challenging. In order to meet requirement of present day applications and to overcome from routing challenges, routing protocols in mobile ad hoc networks need to perform better in terms of certain QoS (Quality of Service) parameters such as; good throughput, sustained communication links and least delay in establishing a link. In this paper, we have discussed QoS in MANETs and analyzed the OLSR (Optimized Link State Routing), a well-known routing protocol in MANETs for possible improvements in its performance. Here, we have revised attributes of core parameters of the standard OLSR routing model in order to obtain a new OLSR design. Performances of the standard and revised OLSR models have been tested and compared under different network scenarios using network simulator-3 (NS-3). Different QoS and performance evaluating metrics such as; the throughput, packet delivery ratio, end to end delay, packet loss and normalized routing load have been considered for measuring performances of either OLSR routing models. Based on the analysis, it is concluded that the revised OLSR model has shown better performances as compared to standard OLSR routing model.
\end{abstract}

Index Terms-MANETs, QoS, OLSR, Routing, Simulation.

\section{INTRODUCTION}

Mobile ad hoc networks often simply called as MANETs are new generation self-forming and selfhealing wireless networks operate without requiring any centralized networking infrastructure such as; central network gateways, base stations or wireless access points. These networks consist of small or large set of randomly moving nodes. Due to random mobility of nodes, topology of these networks becomes dynamic. Nodes have to act as host and the router due to absence of network infrastructure. MANETs function with bandwidth-constrained wireless links and resourceconstrained nodes. Many routing protocols have been proposed for MANETs in the past, among them wellknown are: AODV (Ad hoc On Demand Distance Vector), DSDV (Destination Sequenced Distance Vector), DSR (Dynamic Source Routing) and OLSR (Optimized Link State Routing). The key challenges that a MANET routing protocol faces are: mobility of nodes, hidden and visible terminal problems, error-prone channel state and resource or energy constraints.

MANET routing protocols can be classified into various types based on various criteria, these can be broadly classified into four main categories based on: usage of specific resources, topology of routing, usage of time-based information for routing and routing information update mechanism [1, 2, 3, 4]. However, the classification of these routing protocols is not exclusive because of their presence in multiple classes [1]. Out of which, based on the routing information update mechanism, these are classified into three categories namely, proactive or table-driven, reactive or on-demand and hybrid routing protocols [5]. Hybrid routing protocols are designed by combining the features of proactive and reactive routing protocols. Though mobile ad-hoc networks propose many possibilities, fruitful deployments need genuine solutions to various problems. These problems can be QoS (Quality of Service) 
provisioning, applications built on real-time, supportive functioning, effective energy relaying, provision for multicast traffic and load balancing. Fig.1 illustrates formation of a mobile ad hoc network by eleven numbers of nodes ' $N$ '.

MANET nodes communicate with one another through multi-hop wireless (radio) links. Prime responsibility of the routing protocols is to establish efficient and error free communication links (paths) between network nodes as and when required.

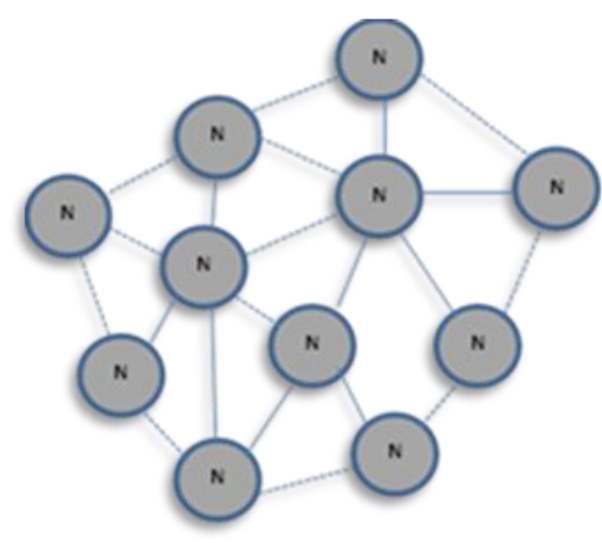

Fig.1. Formation of Mobile Ad-hoc Network

Quality of service in mobile ad hoc networks can be achieved by obtaining good network throughput, minimum packet losses, lesser end to end delay and minimum routing overheads. OLSR is a proactive or table-driven routing protocol that works on an efficient link state mechanism called MPR (Multi Point Relaying). OLSR was developed by employing optimization techniques into the conventional pure link state routing protocol. This paper addresses QoS in MANETs and extensive comparative performance analysis on OLSR routing protocol. Attributes of the core protocol parameters were revised to obtain a new OLSR design and performances of the standard and revised OLSR model have been evaluated by the help of network simulator (NS-3). This paper concludes improved performances of the revised model in terms of QoS and performance evaluating parameters.

\section{RELATED WORK}

Over the years, many researches have been conducted to address performance improvements, issues and challenges in mobile ad hoc networks. Some researchers have worked upon performance comparison of different set of standard routing protocols available for MANETs. Some of them are discussed here; Asutosh Sharma and Rajiv Kumar have studied "performance comparison and detailed study of AODV, DSDV, DSR, TORA and OLSR routing protocols in ad hoc networks" considering standard routing models of these protocols. Their results conclude better performance of the AODV routing protocol in terms of average throughput and packet delivery ratio [6]. Md. Niaz Imtiaz et al., have studied "performance evaluation of routing protocols (AODV, DSR, OLSR and DYMO) in MANET considering mobility factor", their conclusion reveals better performance of OLSR routing protocol [7]. Rakesh Kumar Jha and Pooja Kharga have studied "comparative performance analysis of AODV, DSDV, OLSR and DSR using NS3 Simulator", their study was on conventional models of these routing protocols for different node densities [8].

Dinesh Singh et al., have studied "comparative performance analysis of LANMAR, LAR1, DYMO and ZRP routing protocols in MANET using random way point mobility model" considering varied node pause time. Their analysis concludes better performances of the LANMAR routing protocol [9]. Lakshman Naik et al., have studied performance comparison of conventional and revised models of AODV (Ad hoc On Demand Distance Vector), DSDV (Destination Sequenced Distance Vector) and DSR (Dynamic Source Routing) routing protocols in MANETs, their conclusion reveals improved performances in revised routing models [10, 11, 12]. Sweta Kriplani and Rupam Kesharwani have studied malicious nodes identification and classification of nodes and detection of UDP flood attack with ICMP using OLSR Routing Protocol in MANET [13].

Madhu Bala and Harpreet Kaur have reviewed various routing protocols in MANETs under different network scenarios [14]. Qutaiba Razouqi et al., have studied "extensive performance analysis of standard DSDV, DSR, and AODV routing protocols for different network scenarios", their study declares better behaviour of DSR and AODV routing protocols for combined traffic scenarios [15]. Kanu Bala and Monika Sachdeva have studied "enhancement of OLSR routing protocol in MANET" proposing a new version of the OLSR routing protocol using node grouping techniques, their conclusion discloses better performance of the newly proposed protocol [16]. Ashutosh Dixit and Sandeep Kumar Singh have studied "Performance Evaluation of DSDV, AODV and DSR Routing Protocol in MANET", they conclude better performance of the DSDV routing protocol [17].

Researchers Ying Ge, Thomas Kunz and Louise Lamont have worked on OLSR integration with QoS routing and proposed two theorems which are optimal towards providing up with the highest bandwidth route guarantee between the communicating nodes [18, 19]. Unlike other QoS routing protocols which find a single route between nodes fulfilling the QoS requirements, the OLMQR (On-demand Link state Multipath QoS Routing) routing protocol seeks for multiple routes which jointly gratify the QoS requirements [20]. In OLMQR, total bandwidth required is divided into sub-bandwidths; the routes established by the multipath routing protocol are permitted to share the same sub-routes.

This paper addresses comparative performance analysis of standard and revised OLSR routing models in three scenarios; considering different node densities, different node velocities and different node transmit power. Based on obtained simulation results, performances of either OLSR routing models have been 
calculated by the help of performance evaluating metrics. As compared to standard OLSR model, the revised OLSR model has shown improved performances in terms of QoS and performance evaluating parameters.

\section{QuALITY OF SERVICE (QOS) IN MANETS}

In MANETs, quality of service relates to quality performance level of the network, quality of the services offered by the network and better usage of resources.

\section{A. Network Performance Quality}

In order to offer better quality performance level, a network must achieve better throughput, less delay, minimum data packet losses and lesser routing overheads. In other words, network performances can be improved by some factors such as; better usage of bandwidth, loop free routes, sustained and error free communication links etc.

\section{B. Quality of Service offered by the Network}

It relates to the performance level of the service that a network offers. It determines network services offered to its users, improvements in quality and better use of resources. The purpose of QoS facility is to deliver fine use of network resources. Offered Network services to the users can be measured by factors like; rate of maximum packet loss, jitter, delay level and bandwidth [1, $2,21]$. Delay comprises of various delays such as packet queuing delay, propagation delay and transmission delay, maximum variation in delay is termed as jitter. User's requests need to be fulfilled by the service providing network through some kind of service guarantee. In other words, users of the network must get quality of the service as per their expectations. Quality of service provision must process the user's requests by providing loop-free routes along with the required resources.

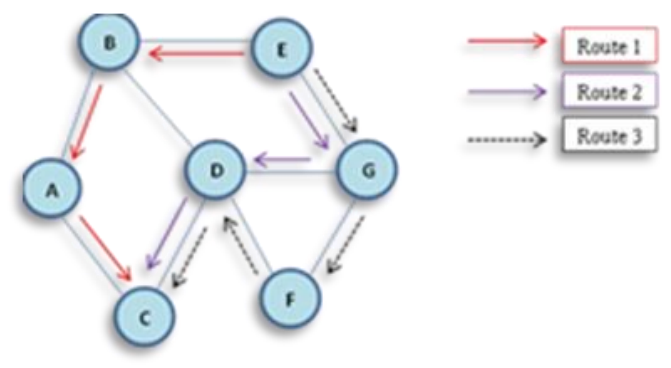

Fig.2. QoS routing in MANETs

The process of providing suitable loop-free routes which fulfills QoS supplies as desired by the services is called QoS routing. After the route finding process, the resource reservation protocol is engaged to ensure requisite resources along the route. QoS assurances can be provided through some resource reservation procedures. Fig.2 illustrates functioning of QoS routing in a mobile ad-hoc network. Here, there are seven network nodes namely A, B, C, D, E and F. For instance, a packet stream is required to establish between the node $\mathrm{E}$ and node $\mathrm{C}$ with a BW (Band Width) assurance of $5 \mathrm{Mbps}$, then the QoS routing protocol seeks a best route that caters the required bandwidth. There are three routes in between the node $\mathrm{E}$ and node $\mathrm{C}$; they are E-B-A-C, E-GD-C and E-G-F-D-C.

Table 1. Link Attributes

\begin{tabular}{|c|c|c|c|c|}
\hline Route No. & Route & $\begin{array}{c}\text { Hop } \\
\text { Count }\end{array}$ & $\begin{array}{c}\text { BW } \\
(\mathrm{Mbps})\end{array}$ & $\begin{array}{c}\text { EED } \\
(\mathrm{ms})\end{array}$ \\
\hline Route1 & E-B-A-C & 3 & 5 & 13 \\
\hline Route2 & E-G-D-C & 3 & 8 & 17 \\
\hline Route3 & E-G-F-D-C & 4 & 7 & 21 \\
\hline
\end{tabular}

Here, QoS routing protocol picks route1 that is E-B-A$\mathrm{C}$ because, out of all the three routes, route1 only can provide the necessary bandwidth of $5 \mathrm{Mbps}$. Route 1 may or may not be optimal in terms of other link attributes such as hop count and EED (End to End delay). Further available routes may be optimal in terms of hop count and EED. Table1 illustrates the link attributes of the overhead network. Different packet flow has their own QoS requirements. QoS routing protocols have to seek the best optimal routes with enough resources to fulfill these QoS requirements. Management modules of the QoS routing protocols manage resource availability along the specific routes.

In mobile ad hoc networks, the topological information maintained by the nodes assists the QoS routing protocols. QoS routing protocols often face performance degradation due to trade-off effects [1, 2, 17, 21, 22]. When path break occurs, these routing protocols either recompute the broken paths or bypass those paths without degrading QoS requirement level. Some examples of QoS routing protocols are: triggered-based distributed [17, 23], ticket-based [17, 24] and predictive location-based [17, 25] QoS routing protocol.

\section{OPtIMIZED LinK STATE Routing}

The optimized link state routing (OLSR) is one of the proactive routing protocol for mobile ad-hoc networks [8, 26, 27, 28]. The OLSR works on multipoint relaying, which is an effective mechanism through which link state packet forwarding takes place. OLSR optimizes the original link state routing protocol; optimizations in OLSR are done in two methods: One is by reducing control packet sizes and another is by reducing those numbers of links which are used for forwarding the packets of the link state [1]. The link state size reduction is done by announcing only a subset of links which are available in the updates of link state. These subsets are the neighbors of every node in the network; subsets are selected for carrying link state updates. These subsets of neighbor nodes are responsible for packet forwarding known as MPRs (Multi Point Relays).

Periodic link state updates are possible due to use of these multi point relays in the process of optimization. During the creation of new links or when an existing link breaks, the link state update mechanism does not produce 
any extra control packets. In dense deployment of mobile ad-hoc networks, the optimization of link state updating realizes higher efficiency.

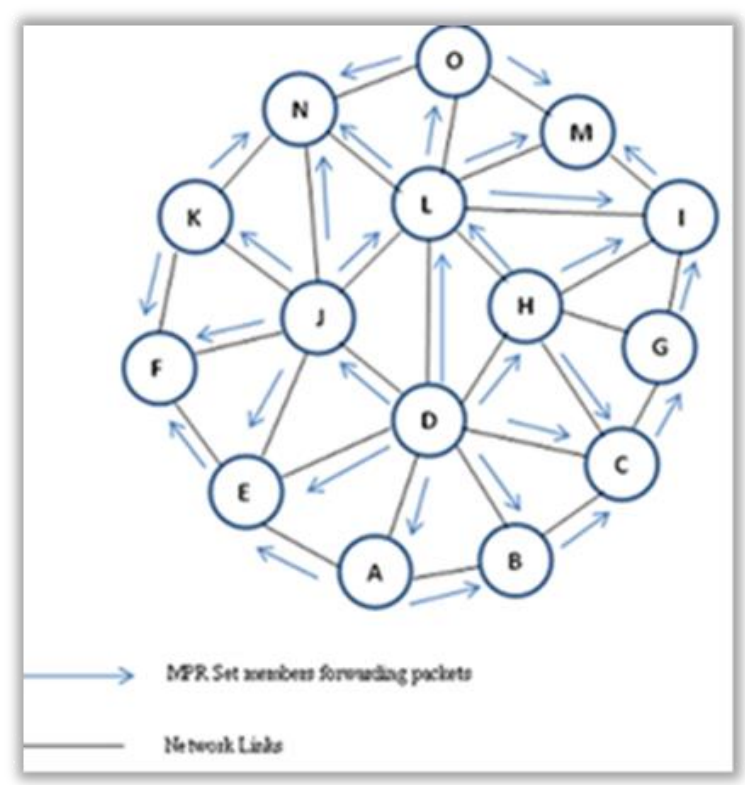

Fig.3. Flooding in OLSR

Fig.3 illustrates flooding process in OLSR. Here, the number of transmissions is almost equal to the number of nodes. In OLSR, subset nodes which act as multipoint relays are also known as MPR set. Each and every node in the network chooses its MPR set and these MPR sets execute the processing and forwarding of link state packets which are originally produced by the leading node of these MPR sets. Other nodes in the network which are not the member of these MPR sets can only process the link state packets so generated by the leading node, but they do not forward the packets. Each and every node in the network retains MPR selectors, which are the neighbour nodes of the network nodes. Associates of MPR selectors and MPR set keep varying time to time. Associates are selected in such a fashion that each node in that node's two-hop neighbourhood possesses bidirectional links. Each node in the network evaluates paths to the destination through the associate nodes in the MPR set; therefore, these MPR sets are expressively responsible in achieving the better performance of the OLSR.

Nodes in the network conclude their MPR set by transmitting HELLO messages. These messages hold the neighbour list of the nodes with which the node already has bidirectional links. HELLO message also holds the information pertaining to the MPRs (Multi Point Relays). Nodes that collect these HELLO messages then update their two-hop topology tables. Each node in the network holds neighbour table. These tables are utilized for storing information such as; list of neighbours, position of the neighbour nodes and the two-hop neighbours. Neighbour nodes in the network are found in three possible link states which are; a multi-point relay, unidirectional and bidirectional.
Every entry in the neighbour tables has a related value of timeout, stale entries in the neighbour tables are deleted by the help of timeout values when they reach expiry. Every MPR set has a sequence number which get increased with the new sets of multi point relays. When network initialization takes place, the MPR sets remain same like in neighbouring set, these MPR sets does not require to be optimal. When a MPR set holds less number of nodes, efficiency of the routing protocol increases equated to link state routing. The network node updates its MPR set upon detecting a new bidirectional link in its neighbourhood or a bidirectional link gets broken in its neighbourhood.

Network nodes generate TC (Topology Control) messages periodically. TC messages hold information associated with the network topology, they update routing tables of the nodes. OLSR has four types of control messages namely, HELLO, TC, HNA (Host and Network Association) and MID (Multiple Interface Declaration) $[28,32]$. HELLO messages contain information related to the link status and host neighbour details. TC messages help in broadcasting neighbours of the nodes in the network. HNA messages are broadcasted to share external routing information; it holds information associated with the network. MID messages are transmitted all over the network to inform the nodes in the network that the host has the potential of establishing multiple interfaces of the routing protocol [8, 27, 28]. OLSR has many advantages which render it better as compare to other MANET proactive routing protocols. OLSR reduces the routing overhead related to the proactive or table-driven routing, besides reducing the number of broadcasts completed.

\section{PERformance Evaluating Metrics}

There are numerous metrics available for evaluating performances of a typical mobile ad-hoc network. Here, we have discussed a few such metrics [8, 28, 29].

\section{A. Throughput}

It is the amount of data transmitted from the source to the destination through the network in a unit time expressed in Kilobits per second (Kbps).

$$
\text { Throughput }=\frac{(\text { Total Bytes Received } \times 8)}{(\text { Simulation Time } \times 1024)}
$$

Higher values of throughput offer better and improved performance. It is derived in Kilobits per second.

\section{B. PDR (Packet Delivery Ratio)}

It is the ratio of packets received to that of total packets sent.

$$
\text { PDR }=\frac{(\text { Total Received Packets })}{(\text { Total Sent Packets })} \times 100 \%
$$

Higher values of PDR deliver improved and higher performance. It is derived in \% (percentage). 


\section{EED (End to End Delay)}

It is the average time interval between packets generated at the source and effective transfer of these packets at the destination.

$$
\mathrm{EED}=\frac{\text { Delay Sum }}{\text { Total Received Packets }}
$$

Smaller values of end to end delay deliver better and higher performance. It is derived in mille second (ms).

\section{PL (Packet Loss)}

It is the difference between the total sent packets and the total received packets.

$\mathrm{PL}=($ Total Packets Sent $)-($ Total Packets Received $)$

PL values must be lesser for better performance. PL is derived in number of packets.

\section{E. NRL (Normalized Routing Load)}

It is a fraction of number of routing packets transmitted to the overall data packets received [15].

$$
\mathrm{NRL}=\frac{\text { Number of Routing Packets Sent }}{\text { Number of Total Data Packets Received }}
$$

Higher values of NRL deliver better and enhanced performance however, larger values of NRL lead to lesser efficiency in terms of consumption of bandwidth.

\section{Simulation SetUP}

Simulation setup involves the successful installation and testing of Network Simulator-3 (NS-3, Version: 3.13) on CENTOS Linux (an open source server graded Linux) platform. "Network Simulator-3 is a discrete-event network simulator in which the simulation core and models are implemented in C++". Almost all the APIs (Application Program Interfaces) of NS-3 have been exported to Python in order to allow Python programs to import NS-3 modules. As compare to NS-2 (Network Simulator-2), NS-3 has enhanced simulation capabilities. NS-3 is not rear attuned with the NS-2; NS-3 was developed from the scratch in order to replace NS-2 APIs.

NS-3 is developed mainly for research and educational use. NS-3 is an open-source network simulator attempts to continue an open environment for researchers for sharing and contribution of software developed by them [30]. General simulation parameters of our network model have been listed in Table 2 [28, 29]. Various core parameters of the standard OLSR algorithmic model have been fine tuned for possible progress in the performance of the OLSR routing protocol. Performance of the standard and revised OLSR model has been evaluated and compared using various performances evaluating metrics discussed at section 5. Revised core parameters of the standard OLSR model have been listed in Table 3 [29] followed by different parameter metrics.

In this simulation model, nodes take their movements in a $300 \times 1500 \mathrm{~m}$ rectangular network region as per the random way point mobility model without pause or halt time. 10 numbers of source/sink node pairs initiate transmission of the data packets to their neighbouring nodes. Destination nodes receive data packets through their neighbours; total time set for the entire simulation process is 150 seconds. Different node population, speed and transmit time have been considered in three different scenarios. Fig.4 explores OLSR script under execution on CentOS platform. Results with appropriate comments have been discussed in section 7 and conclusions are available in section 8 of this paper.

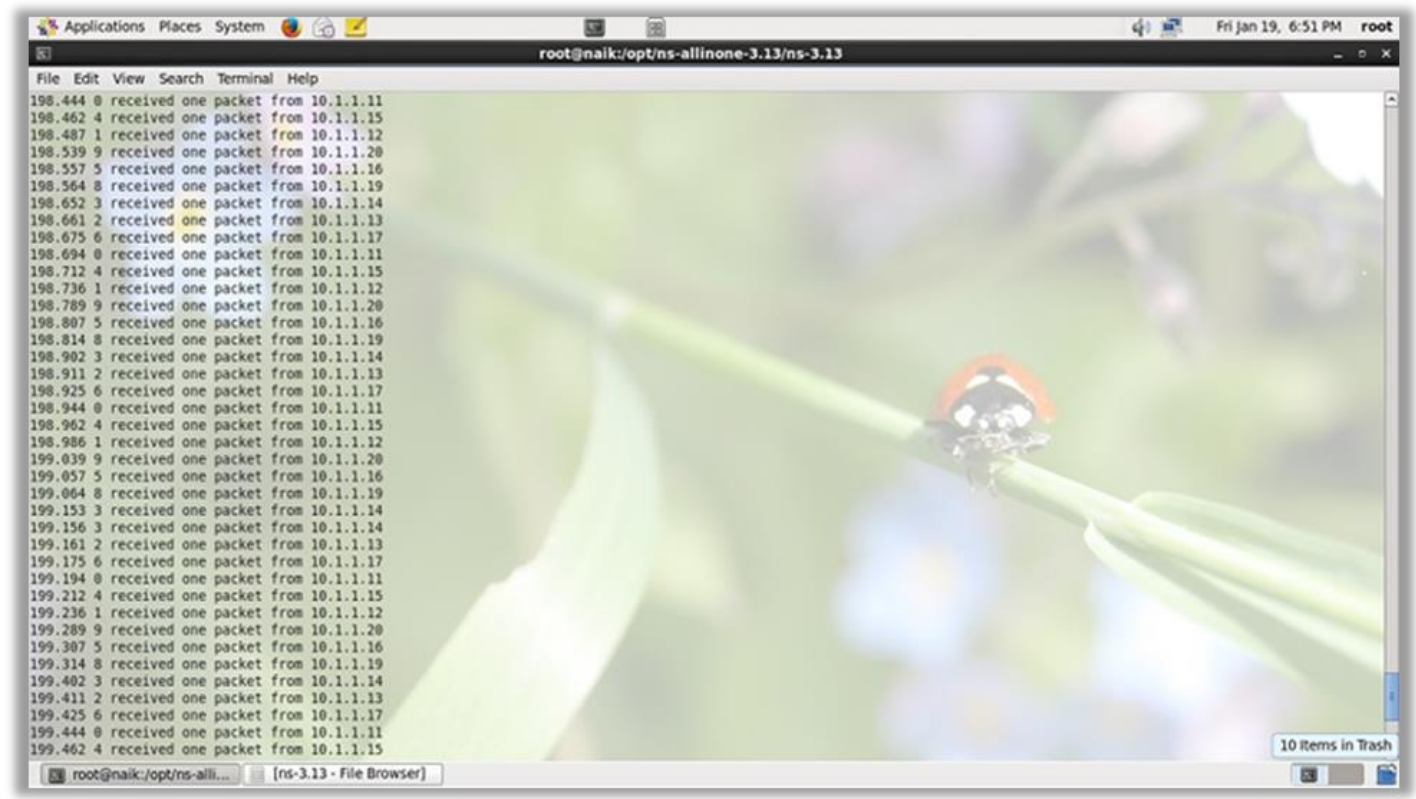

Fig.4. OLSR Script under execution (Screen Shot) 
Revised routing attributes of the standard OLSR routing model are specified in Table 3 [29, 31, 33]. These attributes have been revised for possible performance enhancements in the OLSR routing protocol.

Table 2. General Network Parameters

\begin{tabular}{|c|c|}
\hline $\begin{array}{c}\text { Network } \\
\text { Parameter }\end{array}$ & Assigned Value \\
\hline Network Nodes & $\begin{array}{c}\text { First Scenario: } \\
\text { 30,40,50,60,70,80,90,100 } \\
\text { Second \& Third Scenario: } 50\end{array}$ \\
\hline Set Simulation Time & 150 seconds \\
\hline Set Pause Time & No pause time \\
\hline Wi-Fi mode & Ad-hoc \\
\hline Wi-Fi Rate & 2Mbps (802.11b) \\
\hline Transmit Power & $\begin{array}{l}\text { First and Second Scenario: } 7.5 \mathrm{dBm} \\
\text { Third Scenario: } \\
3.5,4.5,5.5,6.5,7.5,8.5,9.5,10.5 \mathrm{dBm}\end{array}$ \\
\hline $\begin{array}{l}\text { Node Mobility } \\
\text { model }\end{array}$ & $\begin{array}{c}\text { Random Waypoint mobility model } \\
\text { (RWMM) }\end{array}$ \\
\hline Source/Sink pairs & 10 No.s \\
\hline Sent Data Rate & $2.048 \mathrm{Kbps}$ (2048 bits per second) \\
\hline Data Packet Size & 64 Bytes \\
\hline $\begin{array}{l}\text { Node Mobility } \\
\text { Speed }\end{array}$ & $\begin{array}{c}\text { First and Third Scenario: } 20 \mathrm{~m} / \mathrm{s} \\
\text { Second Scenario: } \\
\text { 10,20,30,40,50,60,70,80 m/s }\end{array}$ \\
\hline $\begin{array}{l}\text { MANET Protocols } \\
\text { used }\end{array}$ & Standard and Revised OLSR \\
\hline Network Region & 300x1500 m (Rectangular) \\
\hline Traffic & CBR (Constant Bit Rate) \\
\hline
\end{tabular}

Table 3. Revised Attributes of OLSR Parameters

\begin{tabular}{|c|c|}
\hline Protocol Parameter & Assigned Value \\
\hline Refresh Interval & 2 Seconds \\
\hline Unspecified link & Set to 0 \\
\hline Asymmetric link & Set to 1 \\
\hline Symmetric link & Set to 2 \\
\hline Lost link & Set to 3 \\
\hline Not neighbor & Set to 0 \\
\hline Symmetric neighbor & Set to 1 \\
\hline Asymmetric neighbor & Set to 2 \\
\hline $\begin{array}{c}\text { Maximum number of } \\
\text { messages per packet }\end{array}$ & 64 \\
\hline $\begin{array}{l}\text { Maximum number of } \\
\text { HELLOS per message }\end{array}$ & 12 \\
\hline $\begin{array}{c}\text { Maximum number of } \\
\text { addresses on a message }\end{array}$ & 64 \\
\hline Maximum allowed jitter & 4 Seconds \\
\hline HELLO Interval & 4 Seconds \\
\hline $\begin{array}{c}\text { TC messages emission } \\
\text { interval }\end{array}$ & 3 Seconds \\
\hline $\begin{array}{c}\text { MID messages emission } \\
\text { interval }\end{array}$ & 2 Seconds \\
\hline $\begin{array}{c}\text { HNA messages emission } \\
\text { interval }\end{array}$ & 3 Seconds \\
\hline $\begin{array}{c}\text { Willingness of a node to carry } \\
\text { and forward traffic for other } \\
\text { nodes }\end{array}$ & $\begin{array}{c}\text { Set to: } \\
\text { "OLSR_WILL_ALWAYS" }\end{array}$ \\
\hline Dup holding time & 30 Seconds \\
\hline
\end{tabular}

\section{A. OLSR Holding Time Metrics}

1. Neighbor Holding Time $=(3 \times$ OLSR Refresh Interval $)$

2. Top Holding Time $=(3 \times \mathrm{TC}$ messages emission interval)

3. MID Holding Time $=(3 \times$ MID messages emission interval)

$$
\begin{aligned}
& \text { 4. HNA Holding Time }=(3 \times \text { HNA messages } \\
& \text { emission interval })
\end{aligned}
$$

\section{RESULTS AND DISCUSSIONS}

In our earlier studies, we have conducted extensive analysis on attribute revised models of standard AODV, DSDV and DSR routing protocols to test their performances. Our conclusion reveals improved performances in revised routing models [10, 11, 12]. Researcher Yufei Cheng [34] studied performance analysis of transactional traffic in mobile ad-hoc networks. This analysis includes fine tuning of routing attributes of the standard AODV, DSDV, OLSR and DSR routing protocols to test different traffic transactions in the performance of the mobile ad-hoc networks. Researchers Nurul I. Sarkar et al. [35] studied AODV, DSR, OLSR and TORA (Temporally Ordered Routing Algorithm) routing protocols by considering the factors like; joint node density, packet length and mobility. This study includes fine tuning of routing attributes of the protocol parameters.

In present study, the standard OLSR routing attributes were revised extensively and tested for possible performance improvements in OLSR routing protocol model. Here, attributes revised model referred as the Revised OLSR (R.OLSR). Simulation based experiments on standard and revised OLSR models were carried out in three scenarios. Network parameters in all the scenarios were set as per Table-2. In the first scenario, the typical MANET was tested for different set of network nodes i.e. $30,40,50,60,70,80,90$ and 100 set of nodes. Where, node velocities was set to $20 \mathrm{~m} / \mathrm{s}$ with a transmit power of $7.5 \mathrm{dBm}$. Obtained data for various performances evaluating metrics have been tabulated in Table 4. In the second scenario, different node velocities were considered for a set of 50 nodes with a transmit power of $7.5 \mathrm{dBm}$. Diverse node speeds considered for the experiments were; 10, 20, 30, 40, 50, 60, 70 and $80 \mathrm{~m} / \mathrm{s}$. Evaluated data for different performance calculating metrics are shown in Table 5. In the third scenario, either protocol models were tested for different transmit powers; $3.5,4.5,6.5,7.5,8.5,9.5$ and $10.5 \mathrm{dBm}$ keeping 50 number of mobile nodes with a node velocity of $20 \mathrm{~m} / \mathrm{s}$. Calculated values for different metrics are shown in Table 6. 
Table 4. Data Sheet of Different Node Densities

\begin{tabular}{|c|c|c|c|c|c|c|c|c|c|c|}
\hline \multirow{2}{*}{$\begin{array}{l}\text { No.of } \\
\text { Nodes }\end{array}$} & \multicolumn{2}{|c|}{ Throughput in Kbps } & \multicolumn{2}{|c|}{$\begin{array}{l}\text { Packet Delivery Ratio } \\
\text { in } \%\end{array}$} & \multicolumn{2}{|c|}{$\begin{array}{l}\text { End to End delay in } \\
\text { mille seconds }\end{array}$} & \multicolumn{2}{|c|}{ Packet Loss } & \multicolumn{2}{|c|}{ Normalized Routing Load } \\
\hline & S.OLSR & R.OLSR & S.OLSR & R.OLSR & S.OLSR & R.OLSR & S.OLSR & R.OLSR & S.OLSR & R.OLSR \\
\hline 30 & 18.27 & 18.96 & 91.33 & 94.78 & 2.37 & 1.38 & 520 & 313 & 0.913 & 0.948 \\
\hline 40 & 16.93 & 18.66 & 84.67 & 93.28 & 4.53 & 1.80 & 920 & 403 & 0.847 & 0.933 \\
\hline 50 & 17.99 & 18.95 & 89.93 & 94.75 & 2.80 & 1.39 & 604 & 315 & 0.899 & 0.948 \\
\hline 60 & 18.91 & 19.08 & 94.55 & 95.38 & 1.44 & 1.21 & 327 & 277 & 0.946 & 0.954 \\
\hline 70 & 18.99 & 19.11 & 94.97 & 95.57 & 1.33 & 1.16 & 302 & 266 & 0.950 & 0.956 \\
\hline 80 & 18.60 & 18.78 & 93 & 93.92 & 1.88 & 1.62 & 420 & 365 & 0.930 & 0.939 \\
\hline 90 & 17.47 & 18.29 & 87.37 & 91.47 & 3.62 & 2.33 & 758 & 512 & 0.874 & 0.915 \\
\hline 100 & 18.45 & 18.19 & 92.25 & 90.97 & 2.10 & 2.48 & 465 & 542 & 0.923 & 0.910 \\
\hline
\end{tabular}

Table 5. Data Sheet of Different Node Velocities

\begin{tabular}{|c|c|c|c|c|c|c|c|c|c|c|}
\hline $\begin{array}{c}\text { Node } \\
\text { Velocity } \\
\text { in m/s }\end{array}$ & \multicolumn{2}{|c|}{ Throughput in Kbps } & \multicolumn{2}{c|}{$\begin{array}{c}\text { Packet Delivery Ratio } \\
\text { in \% }\end{array}$} & \multicolumn{2}{c|}{$\begin{array}{c}\text { End to End delay in } \\
\text { mille seconds }\end{array}$} & \multicolumn{3}{c|}{ Packet Loss } & \multicolumn{2}{c|}{$\begin{array}{c}\text { Normalized Routing } \\
\text { Load }\end{array}$} \\
\cline { 2 - 13 } & S.OLSR & R.OLSR & S.OLSR & R.OLSR & S.OLSR & R.OLSR & S.OLSR & R.OLSR & S.OLSR & R.OLSR \\
\hline 10 & 18.60 & 18.54 & 92.98 & 92.72 & 1.89 & 1.96 & 421 & 437 & 0.930 & 0.927 \\
\hline 20 & 17.99 & 18.95 & 89.93 & 94.75 & 2.80 & 1.39 & 604 & 315 & 0.899 & 0.948 \\
\hline 30 & 17.86 & 17.96 & 89.32 & 89.78 & 2.99 & 2.84 & 641 & 613 & 0.893 & 0.898 \\
\hline 40 & 16.00 & 17.24 & 79.98 & 86.20 & 6.26 & 4.00 & 1201 & 828 & 0.800 & 0.862 \\
\hline 50 & 16.16 & 16.38 & 80.78 & 81.88 & 5.95 & 5.53 & 1153 & 1087 & 0.808 & 0.819 \\
\hline 60 & 15.69 & 16.03 & 78.47 & 80.17 & 6.86 & 6.19 & 1292 & 1190 & 0.785 & 0.802 \\
\hline 70 & 15.16 & 15.20 & 75.82 & 76.02 & 7.97 & 7.89 & 1451 & 1439 & 0.758 & 0.760 \\
\hline 80 & 13.93 & 14.63 & 69.63 & 73.15 & 10.90 & 9.18 & 1822 & 1611 & 0.696 & 0.732 \\
\hline
\end{tabular}

Table 6. Data Sheet of Different Node Transmit Power

\begin{tabular}{|c|c|c|c|c|c|c|c|c|c|c|}
\hline \multirow{2}{*}{$\begin{array}{c}\text { Transmit } \\
\text { Power in } \\
\mathrm{dBm}\end{array}$} & \multicolumn{2}{|c|}{ Throughput in Kbps } & \multicolumn{2}{|c|}{$\begin{array}{c}\text { Packet Delivery Ratio } \\
\text { in } \%\end{array}$} & \multicolumn{2}{|c|}{$\begin{array}{l}\text { End to End delay in } \\
\text { mille seconds }\end{array}$} & \multicolumn{2}{|c|}{ Packet Loss } & \multicolumn{2}{|c|}{$\begin{array}{c}\text { Normalized Routing } \\
\text { Load }\end{array}$} \\
\hline & S.OLSR & R.OLSR & S.OLSR & R.OLSR & S.OLSR & R.OLSR & S.OLSR & R.OLSR & S.OLSR & R.OLSR \\
\hline 3.5 & 13.31 & 15.36 & 66.53 & 76.82 & 12.58 & 7.55 & 2008 & 1391 & 0.665 & 0.768 \\
\hline 4.5 & 15.18 & 17.34 & 75.90 & 86.68 & 7.94 & 3.84 & 1446 & 799 & 0.759 & 0.867 \\
\hline 5.5 & 16.08 & 17.90 & 80.38 & 89.48 & 6.10 & 2.94 & 1177 & 631 & 0.804 & 0.895 \\
\hline 6.5 & 17.23 & 18.53 & 86.13 & 92.67 & 4.02 & 1.98 & 832 & 440 & 0.861 & 0.927 \\
\hline 7.5 & 17.99 & 18.95 & 89.93 & 94.75 & 2.80 & 1.39 & 604 & 315 & 0.899 & 0.948 \\
\hline 8.5 & 18.16 & 18.93 & 90.82 & 94.63 & 2.53 & 1.42 & 551 & 322 & 0.908 & 0.946 \\
\hline 9.5 & 19.18 & 19.43 & 95.90 & 97.15 & 1.07 & 0.73 & 246 & 171 & 0.959 & 0.972 \\
\hline 10.5 & 19.42 & 19.56 & 97.10 & 97.80 & 0.75 & 0.56 & 174 & 132 & 0.971 & 0.978 \\
\hline
\end{tabular}

\section{A. Throughput}

Fig. 5 presents performances curves of the standard and revised OLSR routing models for different node sets, the revised OLSR model has shown improved performance as compared to its standard version. In 30, 50, 60 and 70 numbers of node sets, better network throughput have been achieved. However, in 40 numbers of nodes set, a growth of $1.73 \mathrm{Kbps}$ observed.

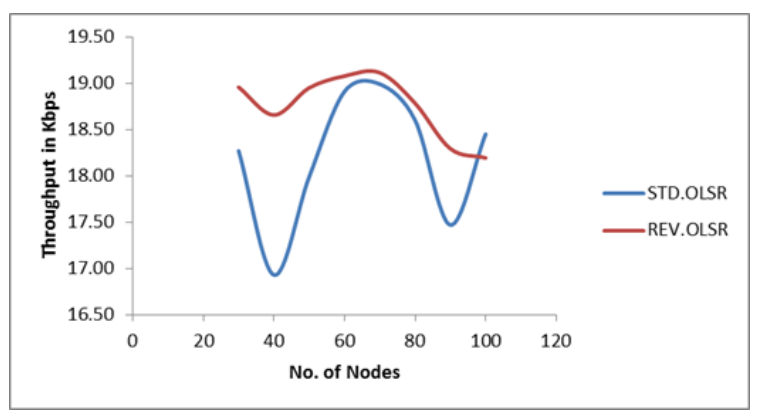

Fig.5. Throughput Vs No.of Nodes
Fig.6 shows throughput graphs of both the routing models for different node velocities. Here, revised model has shown enhanced throughput, for lesser values of node speed, the revised model has gained better throughput. However, for the node speeds $70 \mathrm{~m} / \mathrm{s}$, a slight increment in throughput witnessed.

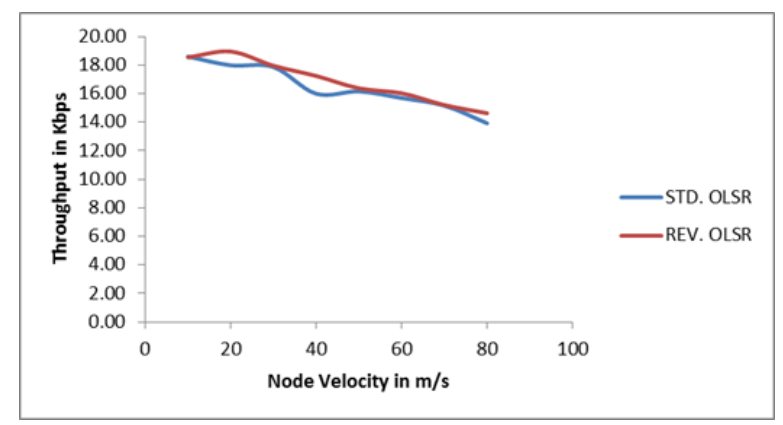

Fig.6. Throughput Vs Node Velocity

In Fig.7, enhanced network throughput can be seen for diverse values of node transmit power. Here, lesser 
values of transmission power gained maximum throughput as compared to higher values, though higher values of transmission power also showed slight increments in network throughput.

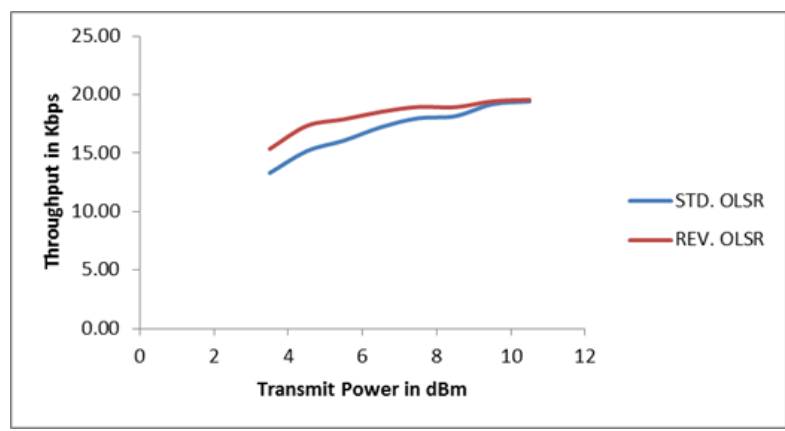

Fig.7. Throughput Vs Transmit Power

\section{B. Packet Delivery Ratio}

Revised OLSR model has shown enhanced results in delivering the data packets to the destination nodes as compare to its standard version for different sets of node densities. Revised OLSR has witnessed peak delivery of 95.57\% packets, whereas standard OLSR has shown better delivery of $92.25 \%$ packets for 100 numbers of nodes. Fig.8 displays the performances of both the routing models, where, revised OLSR has shown improvement in performance for all the set of nodes except for 100 numbers of nodes.

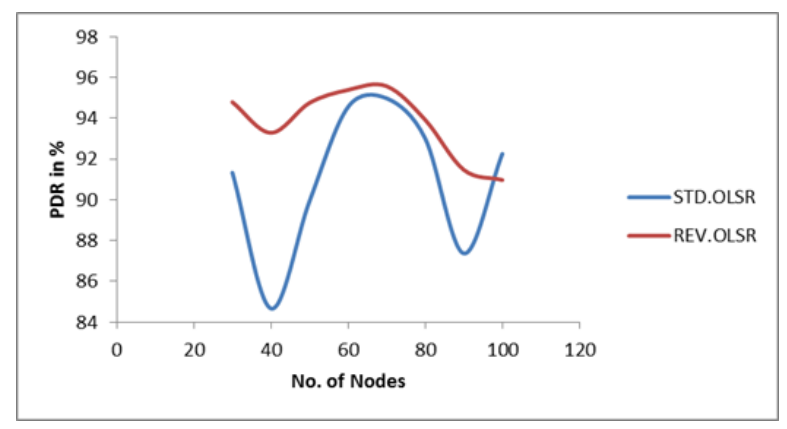

Fig.8. PDR Vs No.of Nodes

For different values of node velocities, the revised OLSR routing protocol has revealed better packet delivery. Fig.9 shows the performances of both the routing protocols, for 20,40 and $80 \mathrm{~m} / \mathrm{s}$, the revised model has shown remarkable data packet delivery.

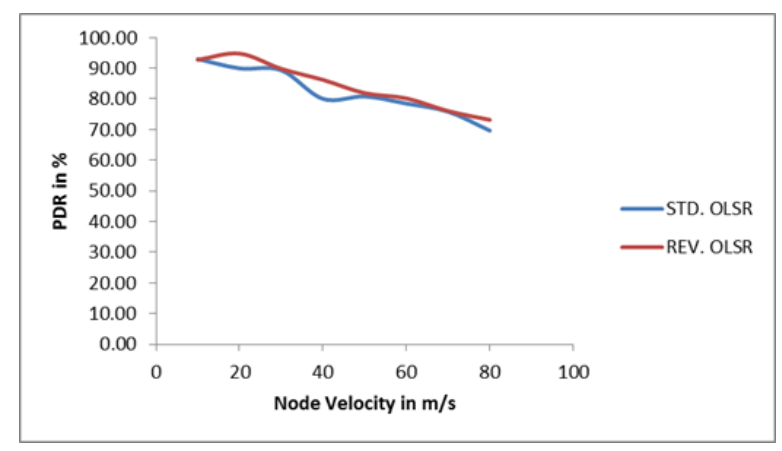

Fig.9. PDR Vs Node Velocity
Fig.10 reveals performances of the standard and revised OLSR routing models for different node transmission power. Here, the revised OLSR model has shown better and improved performance in delivering the data packets from the source to the destination nodes.

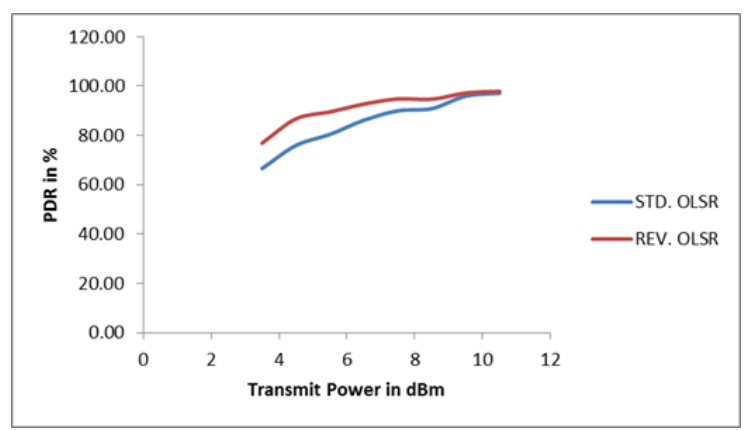

Fig.10. PDR Vs Transmit Power

\section{End to End Delay}

Scenarios of delay in delivering data packets of the revised and standard OLSR protocols have been demonstrated in Fig.11. As compared to the standard OLSR routing, the amended OLSR protocol has met with minimum delays for different sets of nodes. In order to improve performances of the MANET routing protocols, end-to end delay must be minimum.

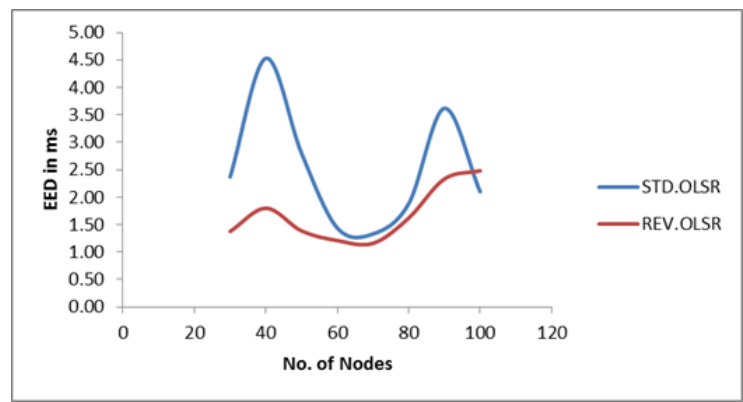

Fig.11. EED Vs No.of Nodes

Fig. 12 illustrates the delay faced by both the routing protocols while transporting data packets from the source to the destination nodes. For some different node velocities, the revised OLSR routing protocol has come across minimum delay as compared to the standard OLSR model. For the node speed $40 \mathrm{~m} / \mathrm{s}$, the revised OLSR met with a minimum delay of 1.8 mille seconds whereas the standard OLSR has 4.53 mille seconds.

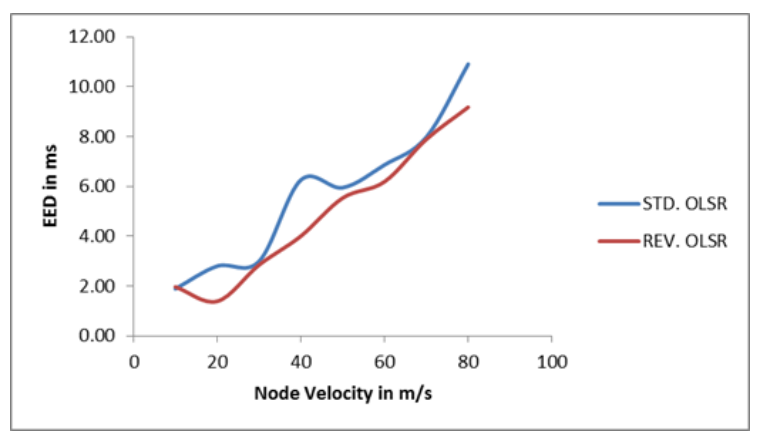

Fig.12. EED Vs Node Velocity 
For different transmit power, the revised OLSR has shown better data packet delivery having minimum packet losses. Fig. 13 shows the performances of both the routing protocols. At 3.5 and $4.5 \mathrm{dBm}$, the revised OLSR has shown the best performance as compared to other values of transmit power.

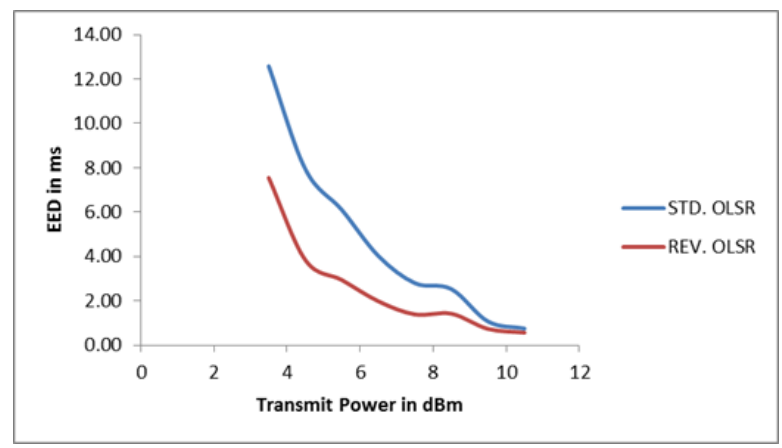

Fig.13. EED Vs Transmit Power

\section{Packet Loss}

Fig.14 displays packet loss graphs of the standard and revised OLSR routing protocols for various node densities. The revised protocol has a minimum packet loss of 266 packets for 70 numbers of nodes, whereas, the standard OLSR has minimum losses 465 packets for 100 numbers of nodes. The amended OLSR model has encountered minimum packet losses during data packet transmission sessions from the source nodes to the destination nodes as compare to the standard OLSR protocol model.

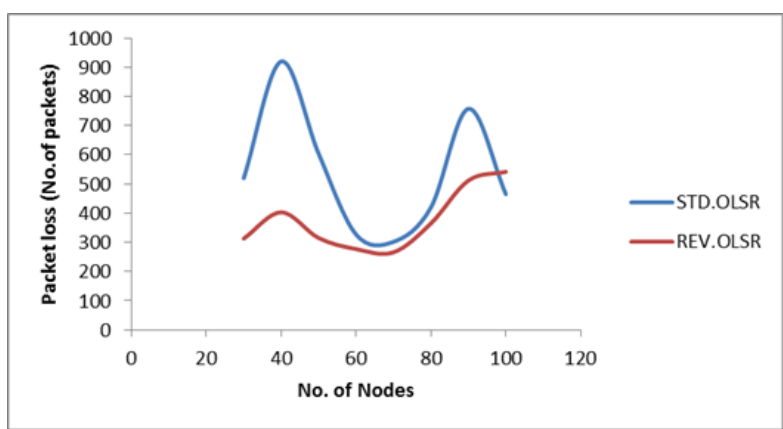

Fig.14. Packet Loss Vs No.of Nodes

The graphical curves shown in Fig. 15 represent packet losses occurred during transmission in the standard and revised OLSR routing protocols. As compared to standard OLSR protocol, the revised protocol has shown better performances having minimum losses and high gain at different node velocities. At node speed of $20 \mathrm{~m} / \mathrm{s}$, the standard OLSR has a loss of 604 numbers of data packets, whereas the revised OLSR lost 315 numbers of packets.

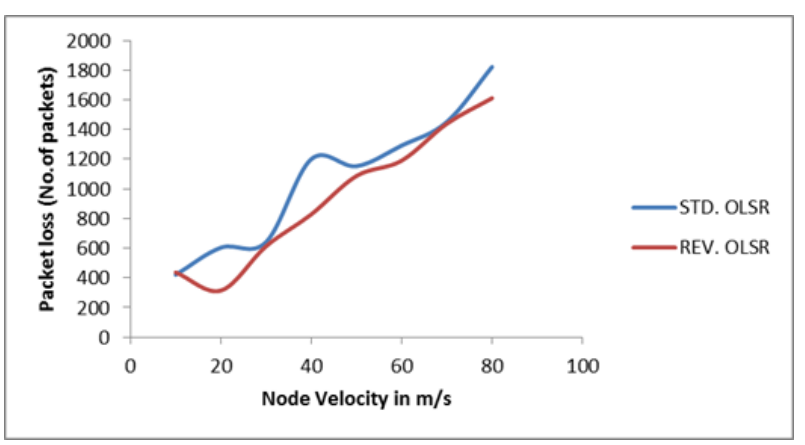

Fig.15. Packet Loss Vs Node Velocity

As opposed to the standard OLSR routing protocol, the revised protocol has performed better by having minimum packet losses for different node transmission power. Fig.16 displays performance curves of both the routing protocols. To $3.5 \mathrm{dBm}$, the standard OLSR has faced a loss of 2008 numbers of packets, whereas the revised OLSR has a loss of 1391 numbers of data packets.

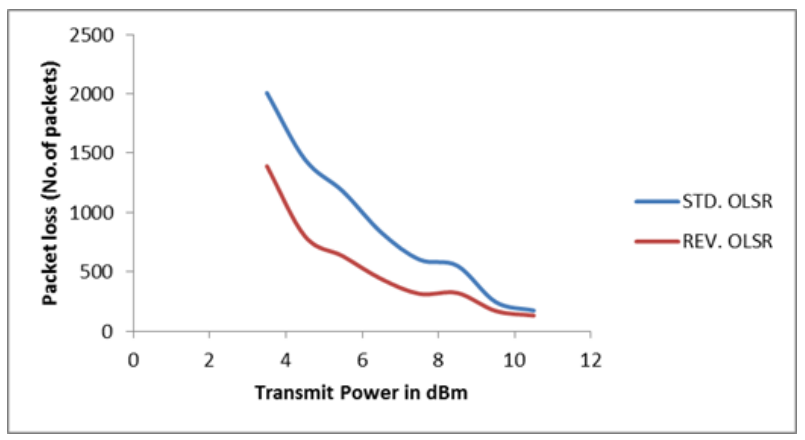

Fig.16. Packet Loss Vs Transmit Power

\section{E. Normalized Routing Load}

Performance curves of Fig.17 reveals routing loads handled by the standard and the revised OLSR routing protocols for different node population scenarios. Like in other metrics discussed above, as compared to the standard OLSR model, the revised OLSR model has performed better in handling routing load for various node densities. Better results of normalized routing load show improved performances of the routing protocol; however it may consume more bandwidth.

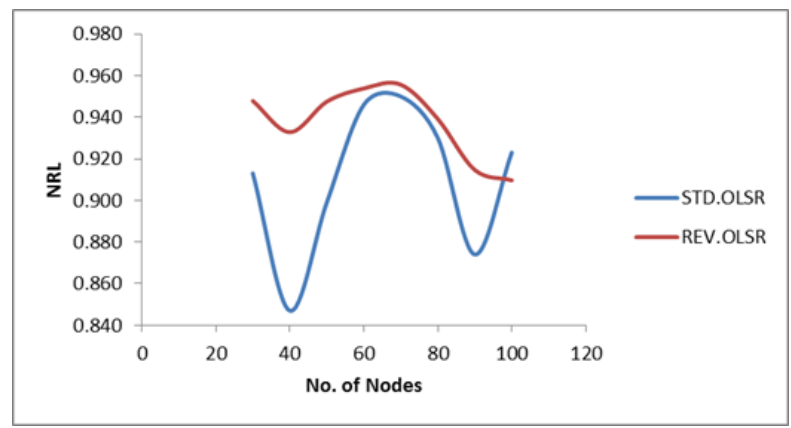

Fig.17. NRL Vs No.of Nodes

Fig.18 shows graphical representation of normalized routing load handled by both the OLSR models with respect to different node velocities. Comparing to the 
standard OLSR model, the revised OLSR has shown better performance in normalizing the routing load.

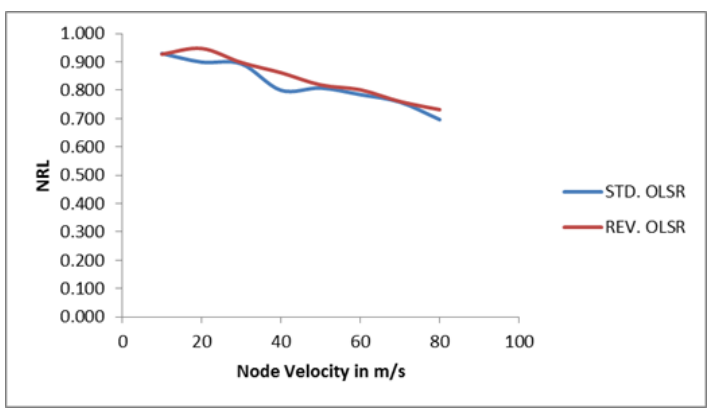

Fig.18. NRL Vs Node Velocity

The normalized routing load versus transmit power graph shown in Fig.19 represents performances of the standard and the revised OLSR routing protocols for different transmit power values. As opposed to the standard OLSR routing, the revised routing model has shown better results in normalizing the routing load and minimizing the routing overheads.

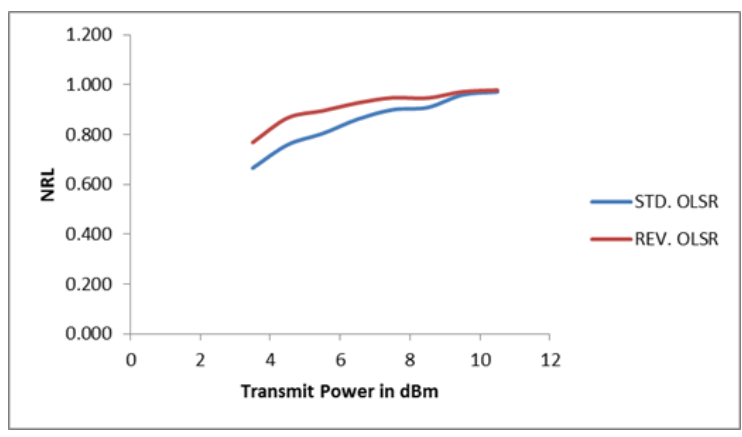

Fig.19. NRL Vs Transmit Power

\section{CONCLUSION}

As per simulation results and metric calculations, the throughput, packet delivery ratio, end to end delay, packet loss and normalized routing load of the revised OLSR model have shown notable performance improvements as compare to its standard version. These results are based on the general network parameters that we set for our analysis and revised parameter attributes of the standard OLSR routing protocol. Attributes of various parameters of the standard OLSR routing protocol have been altered only for testing and study purposes. Further research can be taken onward for large set of nodes, higher values of the node velocities and node transmission power, diverse simulation scenarios including different parameters of the transmission region, transmission range, large or less number of source/sink pairs, different mobility models, different $\mathrm{Wi}-\mathrm{Fi}$ rates, different traffic generators and QoS (Quality of Service) considerations etc.

\section{REFERENCES}

[1] C. Siva Ram Murthy and B.S. Manoj, "Ad Hoc Wireless
Networks Architecture and Protocols", Pearson Education, Inc. First Impresson, 2007.

[2] Basagni, S., Conti, M., Giordano, S. and Stojmenovic, I, "Mobile Ad Hoc Networking, John Wiley \& Sons, Inc., Hoboken, New Jersey, 2004.

[3] D. Helen and D. Arivazhagan, "Applications, Advantages and Challenges of Ad Hoc Networks", Journal of Academia and Industrial Research (JAIR), vol.2, no.8, pp.453-457, January 2014

[4] Naeem Raza, Muhammad Umar Aftab, Muhammad Qasim Akbar, Omair Ashraf, and Muhammad Irfan, "Mobile Ad-Hoc Networks Applications and Its Challenges", Communications and Network Journal, Scientific Research Publishing, vol.8, pp.131-136, August 2016.

[5] Mandeep Kaur Gulati and Krishan Kumar, "A Review of QoS Routing Protocols in MANETs", IEEE International Conference on Computer Communication and Informatics (ICCCI -2013), 04 - 06 January 2013 (Coimbatore, India).

[6] Asutosh Sharma and Rajiv Kumar, "Performance Comparison and Detailed Study of AODV, DSDV, DSR, TORA and OLSR Routing protocols in Ad Hoc Networks", IEEE Fourth International Conference on Parallel, Distributed and Grid Computing, 978-1-50903669-1/16, pp.732-736, 2016.

[7] Md. Niaz Imtiaz, Md. Mohidul Hasan, Md. Imran Ali and Md. Mostak Shaikh, "Performance Evaluation of Routing Protocols (AODV, DSR, OLSR and DYMO) in MANET Considering Mobility Factor", International Journal of Scientific \& Engineering Research, vol.6, no. 12, pp.714720, December 2015.

[8] Rakesh Kumar Jha, Pooja Kharga, "A Comparative Performance Analysis of Routing Protocols in MANET using NS3 Simulator", International Journal of Computer Network and Information Security, MECS publication, vol.4, pp. 62-68, March 2015.

[9] Dinesh Singh, Ashish K. Maurya, Anil K. Sarje, "Comparative Performance Analysis of LANMAR, LAR1, DYMO and ZRP Routing Protocols in MANET using Random Waypoint Mobility Model", IEEE 3rd International Conference on Electronics Computer Technology, vol.6, pp.62-66, IEEE 978-1-4244-8679-3/11, 2011.

[10] Lakshman Naik.L, R.U. Khan and R.B. Mishra, "Analysis of Performance Enhancing Parameters of AODV using NS-3," IEEE African Journal of Computing and ICT, vol. 8, no.2, pp. $87-94,2015$.

[11] Lakshman Naik.L, R.U. Khan and R.B. Mishra, "Analysis of Performance Improving Parameters of DSDV using NS-3," International Research Journal of Engineering and Technology, vol. 3, no.7, pp. 446 - 452, 2016.

[12] Lakshman Naik.L, R.U.Khan and R.B.Mishra, "Comparative Performance Analysis on DSR Routing Protocol in MANETs", Asian Journal of Scientific Research, accepted for publication, January 2018.

[13] Sweta Kriplani and Rupam Kesharwani, "Malicious Nodes Identification and Classification of Nodes and Detection of UDP Flood Attack with ICMP using OLSR Routing Protocol in MANET", International Journal of Scientific Research in Science, Engineering and Technology (IJSRSET), vol.2, no.1, pp.90-94, 2016.

[14] Madhu Bala and Harpreet Kaur, " Review on Routing Protocols in Mobile Ad Hoc Networks", International Journal of Advanced Research in Computer Science, vol.8, no.4, pp.1-5, May 2017.

[15] Qutaiba Razouqi, Ahmed Boushehri, Mohamed Gaballah, Lina Alsaleh, "Extensive Simulation Performance 
Analysis for DSDV, DSR, and AODV MANET Routing Protocols", 27th International Conference on Advanced Information Networking and Applications Workshops. IEEE Computer Society, pp:335-342, DOI:10.1109/WAINA.2013.239, 2013.

[16] Kanu Bala and Monika Sachdeva, "Enhancement of OLSR Routing Protocol in MANET", International Conference on Futuristic Trends in Engineering, Science, Humanities, and Technology (FTESHT-16), Research Bib, vol.3, pp.45-49, January 2016.

[17] Ashutosh Dixit and Sandeep Kumar Singh, "Performance Evaluation of DSDV, AODV and DSR Routing Protocol in MANET", International Journal of Scientific and Research Publications, vol. 5, no.3, March 2015.

[18] Ge, Thomas Kunz and Louise Lamont, "Quality of Service Routing in Ad-Hoc Networks Using OLSR", IEEE Proceedings of the 36thHawaii International Conference on System Sciences, 2002.

[19] [Online].Available:http://citeseerx.ist.psu.edu/viewdoc/do wnload?doi=10.1.1.92.4669\&rep=rep1\&type $=$ pdf

[20] Y. Chen, Y.Tseng, J. Sheu, and P. Kuo, "On-Demand, Link-State, Multipath QoS Routing in a Wireless Mobile Ad Hoc Network", Proceedings of European Wireless 2002, pp. 135-141, Febraury 2002.

[21] Anjana Tiwari and Indrajit Kaur, "Performance Evaluation of Energy Efficient for MANET Using AODV Routing Protocol" 3rd IEEE International Conference on "Computational Intelligence and Communication Technology" (IEEE-CICT 2017), pp.1-5, 2017.

[22] Dr.Sudip Misra, Isaac Zhang, Isaac Woungang and Subhas Chandra Misra, "Guide to Wireless Ad Hoc Networks", Springer, October 2010.

[23] S.De, S.K.Das, H.Wu and C.Qiao, "Trigger-Based Distributed QoS Routing in Mobile Ad Hoc Networks", ACM SIGMOBILE Mobile Computing and Communications Review, vol.6, no.3, pp.22-35, July 2002.

[24] S.Chen and K.Nahrstedt, "Distributed Quality-of-Service Routing in Ad Hoc Networks", IEEE Journal on Selected Areas in Communications, vol.17, no.8, pp.1488-1504, August 1999.

[25] S.H.Shah and K.Nahrstedt, "Predictive Location-Based QoS Routing in Mobile Ad Hoc Networks", Proceedings of IEEE ICC 2002, vol.2, pp. 1022-1027, May 2002.

[26] T.H.Clausen, G.Hansen, L.Christensen, and G.Behrmann, "The Optimized Link State Routing Protocol, Evaluation Through Experiments and Simulation", Proceedings of IEEE Symposium on Wireless Personal Mobile Communications 2001, September 2001.

[27] Lakshman Naik, L., R.U.Khan and R.B.Mishra, "Analysis of Transmit Power Effects in Ad-hoc Network Protocols using Network Simulator-3", International Research Journal of Engineering and Technology (IRJET), vol.3, no.7, pp. $453-459,2016$.

[28] Lakshman Naik L, Khan RU, Mishra RB, "Analysis of Node Density and Pause Time Effects in MANET Routing Protocols using NS-3", International Journal of Computer Network and Information Security (MecsIJCNIS), vol.8, no.12, pp. 9-17, 2016.

[29] Lakshman Naik L, Khan RU, Mishra RB, "Study and Analysis of Different Node Velocity Effects on AODV, DSDV and OLSR", Communicated to International Journal of Electronics and Telecommunications (IJET), 2018.

[30] [Online].Available:https://www.nsnam.org/docs/release/3. 13/tutorial/ns-3-tutorial.pdf

[31] [Online].Available: https://www.nsnam.org/doxygen/olsrrouting-protocol_8cc.html
[32] T. Clausen, \& P. Jacquet, "Optimized Link State Protocol", $\quad$ rfc3626, Available: https://www.ietf.org/rfc/rfc362 6.txt

[33] Lakshman Naik L, Khan RU, Mishra RB, "Comparative Performance Analysis on Revised MANET Routing Protocols", International Journal of Applied Engineering Research (IJAER), vol.13, no.5, pp. 2443-2451, 2018.

[34] Yufei Cheng, "Performance Analysis of Transactional Traffic in Mobile Ad-hoc Networks", Thesis, Department of Electrical Engineering \& Computer Science, School of Engineering, University of Kansas, 2014.

[35] Nurul I. Sarkar., and Wilford G. Lol, "A Study of MANET Routing Protocols: Joint Node Density, Packet Length and Mobility", The IEEE symposium on Computers and Communications, 22-25 June, Riccione, Italy, pp. 515-520. 2010. DOI: 10.1109/ISCC.2010.5546763.

\section{Author's Profiles}

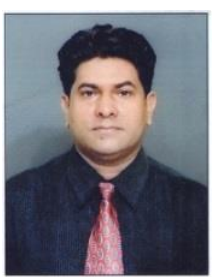

Lakshman Naik.L received Bachelor of Engineering degree in Electronics and Communication Engineering from Gulbarga University, Gulbarga, India. Currently, he has been pursuing Ph.D., in Indian Institute of Technology (Banaras Hindu University), Varanasi, India. Now, he is working as a Maintenance Engineer at Computer Centre of the Banaras Hindu University, in Varanasi, India. He has more than 10 years of experience in maintaining computer Networks, having 5 years of research experience in Engineering and Educational fields. His research interest includes Computer Networks, Wired and Wireless Communication, Mobile Ad hoc Networks, and Network Routing Protocols. He has published several research papers in various international journals.

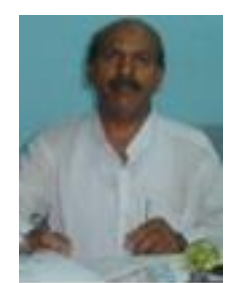

Dr. R.U.Khan is an Associate Professor in Department of Electronics Engineering, Indian Institute of Technology (Banaras Hindu University), Varanasi, India. $\mathrm{He}$ received B.Tech, M.Tech and Ph.D. degree from Banaras Hindu University, Varanasi, India. He has more than 36 years of experience in teaching. His research interests focus on Microwave solid State Devices, Microelectronics, Opto-electronics devices and Computer Networks. $\mathrm{He}$ is guiding for several research scholars under Indian Institute of Technology (Banaras Hindu University), Varanasi, India. He has been published many research articles in National, International Journals and conferences.

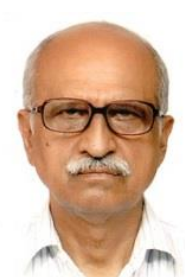

Prof. R.B. Mishra is a Professor in Department of Computer Science and Engineering, Indian Institute of Technology (Banaras Hindu University), Varanasi, India. He received B.Sc.( Engg.), M.Tech (Control) and Ph.D., degree from Banaras Hindu University, Varanasi, India. He has more than 35 years of experience in teaching. His research interests focus on Artificial Intelligence, Multi-agent Systems, Semantic Web and Computer Networks. He has guided $16 \mathrm{Ph} . \mathrm{D}$ scholars under Indian Institute of Technology (Banaras Hindu University), Varanasi, India. He has been 
published more than 230 research articles in Journals and conferences.

How to cite this paper: Lakshman Naik.L, R.U.Khan, R.B.Mishra,"MANETs: QoS and Investigations on Optimized Link State Routing Protocol", International Journal of Computer Network and Information Security(IJCNIS), Vol.10, No.10, pp.26-37, 2018.DOI: 10.5815/ijcnis.2018.10.04 